\title{
Phylogeny of the freshwater lineages within the phyla Actinobacteria (Overview)
}

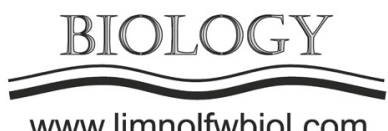

www.limnolfwbiol.com

\section{Lipko I.A.}

Limnological Institute, Siberian Branch of the Russian Academy of Sciences, Ulan-Batorskaya Str., 3, Irkutsk, 664033, Russia

ABSTRACT. This review presents molecular classification of freshwater Actinobacteria based on the phylogeny of the 16S rRNA gene. We show the classification of the entire phylum Actinobacteria and the taxonomic rank of freshwater lineages of Actinobacteria within this phylum. The discovery history of different groups of freshwater Actinobacteria is considered. We have systematized the information about the phylogeny of cultivated and uncultivated freshwater Actinobacteria and give their brief description. Data is provided on freshwater groups of Actinobacteria found in different ecotopes of Lake Baikal.

Keywords: 16S rRNA gene-based phylogeny, phylum Actinobacteria, freshwater lineages of Actinobacteria, Lake Baikal

\section{Introduction}

Phylum Actinobacteria is one of the largest taxonomic units in the domain Bacteria. It consists of gram-positive bacteria with a high G+C DNA content (from 51 to 70\%) (Ventura et al., 2007). Actinobacteria have a diverse morphology, from coccoid (Micrococcus spp.), rod-coccoid (Arthrobacter spp.) forms to fragmenting hyphae (Nocardia spp.) and highly differentiated branched mycelium (Streptomyces spp.). This phylum is widespread, especially in soil, and it includes saprophytes (inhabitants of soil, vegetation, the gastrointestinal tract of animals and humans), symbionts and pathogens (Ventura et al., 2007). Actinobacteria are biotechnologically important producers of various biologically active substances that are widely used in industry, medicine and agriculture (Barka et al., 2016).

It has been long believed that actinobacteria isolated from water are of soil origin, and they do not develop in the aquatic environment, having inactive state in the form of spores (Goodfellow and Williams, 1983). The molecular methods independent of cultivation, mainly such as fluorescent cell labelling and PCR analysis of 16S rRNA gene sequences, revealed that uncultivated members of Actinobacteria are numerous and cosmopolitan inhabitants of freshwater ecosystems, constituting the dominant fraction of heterotrophic bacterioplankton (Glöckner et al., 2000; Zwart et al., 2002; Warnecke et al., 2004; Allgaier and Grossart, 2006; Newton et al., 2011). After evidence of the fundamental difference of freshwater bacterioplankton from soil and marine bacteria has accumulated, Actinobacteria are under the scrutiny of researchers as one of the main groups of the freshwater bacterial community (Methe' et al., 1998; Rappe' et al., 1999; Glöckner et al., 2000; Zwart et al., 2002).

This overview aimed to systematize the taxonomic data on uncultivated and cultivated freshwater Actinobacteria obtained from the phylogeny of the 16S rRNA gene.

\subsection{Molecular classification of the phylum Actinobacteria}

The phylogeny of the 16S rRNA gene divides Actinobacteria into six classes, such as Actinobacteria, Acidimicrobiia, Coriobacteriia, Nitriliruptoria, Rubrobacteria, and Thermoleophilia (Ludwig et al., 2012). According to this classification, the largest class Actinobacteria includes 15 orders, and other classes consist of one-two orders.

In the phylogenetic tree, there are two large clades within the class Actinobacteria. The first clade includes the orders Actinopolysporales, Corynebacteriales, Glycomycetales, Jiangellales, Micromonosporales, Propionibacteriales, and Pseudonocardiales. The second clade includes the orders Actinomycetales, Bifidobacteriales, Kineosporiales, and Micrococcales. The orders Catenulisporales, Streptomycetales, Streptosporangiales, and Frankiales are distinct genetically separated branches within the class Actinobacteria (Ludwig et al., 2012). Analysis of 100 whole-genome sequences of the main families and orders belonging to the class Actinobacteria divided the

*Corresponding author.

E-mail address: irinalipko@yandex.ru (I.A. Lipko) 
order Frankiales into four monophyletic orders, such as Frankiales, Geodermatophilales, Acidothermales, and Nakamurellales (Sen et al., 2014). The order Micrococcales is also polyphyletic and requires additional revision, but officially this cannot be done due to the insufficient number of whole genomes. Thus, at present, the class Actinobacteria includes 18 recovered orders.

\subsection{Discovery of freshwater Actinobacteria}

Uncultivated freshwater Actinobacteria were first discovered in 1997 in the Adirondack Mountain Lakes of the USA (Hiorns et al., 1997). In the phylogenetic tree, they formed an ACK-4 cluster that is separate from other known cultivated actinobacteria. This group of Actinobacteria called hgcI was detected in great numbers in lakes Fuchskuhle (Germany) and Gossenkollesee (Austria) as well as in Lake Baikal (Russia) (Glöckner et al., 2000).

Zwart et al. (2002) showed that freshwater Actinobacteria are autochthonous and cosmopolitan, and he identified five proposed clusters typical of freshwater uncultivated Actinobacteria, which were combined into two large monophyletic groups. The first group, ACK-4 (Hiorns et al., 1997) or hgcI (Glöckner et al., 2000), included clusters ACK-M1 and Sta2-30 (Zwart et al., 2002). The second group of Actinobacteria called C111 (Urbach et al., 2001) included clusters Urk0-14, CL500-29 and Med0-06 (Zwart et al., 2002).

As a rule, the proposed cluster should contain at least two sequences that have at least 95\% similarity and inhabit deep zones of at least two freshwater bodies. According to these conditions, the Luna cluster was the next sixth proposed cluster belonging to the typical freshwater bacteria (Hahn et al., 2003). The members of this cluster were widespread in various freshwater ecosystems of Europe, Asia and North America, and they contained cultivated members having ultramicrobacterial cell sizes (less than $0.1 \mu^{3}$ ) even when grown in a very rich medium. The isolated pure cultures had cells in the shape of a vibrio.

\subsection{Phylogenetic lineages of freshwater Actinobacteria}

Warnecke et al. (2004) first proposed a unified classification of freshwater Actinobacteria. Actinobacterial sequences obtained from various freshwater bodies were grouped into four phylogenetic clusters: acI, acII, acIII, and acIV. These phylotypes were stable in different tree reconstructions (neighbour joining, maximum parsimony and maximum likelihood), and they were separated from the soil and marine lineages of Actinobacteria.

The acI and acII clusters were typical autochthonous freshwater Actinobacteria, and the acIV cluster contained only sequences of uncultivated Actinobacteria from freshwater bodies, marine sediments and soil (Warnecke et al., 2004). The acI was separated into three subclusters: acI-A corresponding to the ACK-M1 cluster, acI-B corresponding to Sta2-30 (Zwart etal., 2002) and new acI-C subcluster (Warnecke et al., 2004). In the acII cluster, the subclusters acII-B and acII-D were identified, corresponding to Luna-1 and Luna-2 (Hahn et al., 2003) and two new groups: acII-A (meromictic lake Sælenvannet, Norway) and acII-C (dystrophic lake Fuchskuhle, eutrophied water body in the Czech Republic and hot springs in New Zealand) (Warnecke et al., 2004). Sequences in the acIII cluster were obtained from chemocline of Lake Sælenvannet (Norway) and corresponded to the sequences of the cluster 2 identified in water of hypersaline soda lake (Humayoun et al., 2003). The acIV cluster was divided into the acIV-A subcluster corresponding to CL500-29 (Zwart et al., 2002) and the acIV-B subcluster (Warnecke et al., 2004).

Newton et al. (2011) supplemented and extended the previous classification by using his data and material accumulated in the databases. Nine freshwater lineages (acI, acTH1, acSTL, Luna1, acIII, Luna3, acTH2, acIV, and $\mathrm{acV}$ ), including more than 40 clusters, were isolated in the phylum Actinobacteria. Phylogenetic lineages acI, acTH1, acSTL, Luna1, acIII, Luna3, and acTH2 belonged to the orders Actinomycetales and Micrococcales (class Actinobacteria), and the lineages acIV and acV - to the order Acidimicrobiales (class Acidimicrobiia) (Newton et al., 2011; Ludwig et al., 2012; Ghai et al., 2014). The 16 S rRNA phylogeny of some freshwater actinobacteria is shown in the figure borrowed from Ghai et al. (2013).

\subsection{Characterisation of uncultivated and cultivated representatives of phylogenetic lineages of freshwater Actinobacteria}

The abundant and widespread actinobacterial groups in freshwater bodies are acI, acIV and Luna1 (Humbert et al., 2009; Newton et al., 2011; Parveen et al., 2011; Martinez-Garcia et al., 2012).

According to the classification of Newton et al. (2011), acI contains 13 clusters. One of the clusters includes 'Candidatus Planktophila limnetica', being the first proposed species of Actinobacteria, which was obtained in the mixed culture (Jezbera et al., 2009). Recently, purecultures of Actinobacteria belonging toacI, which are related to the genera 'Candidatus Planktophila' and 'Candidatus Nanopelagicus', were obtained (Kang et al., 2017; Neuenschwander et al., 2018). These two genera formed a new family ' $\mathrm{Ca}$. Nanopelagicaceae' as well as a new order ' $\mathrm{Ca}$. Nanopelagicales' that formed in the phylogenetic tree a stable related group together with the orders Streptomycetales, Streptosporangiales and Acidothermales (Neuenschwander et al., 2018). 'Candidatus' status is given to genera and species until none of the freshwater groups is represented by a taxon with a reliably published name (Hahn, 2009). The genus 'Candidatus Planktophila' includes six species (' $\mathrm{Ca}$. Planktophila limnetica', 'Ca. Planktophila dulcis', 'Ca. Planktophila sulfonica', 'Ca. Planktophila versatilis', 'Ca. Planktophila lacus', and 'Ca. Planktophila vernalis'), 


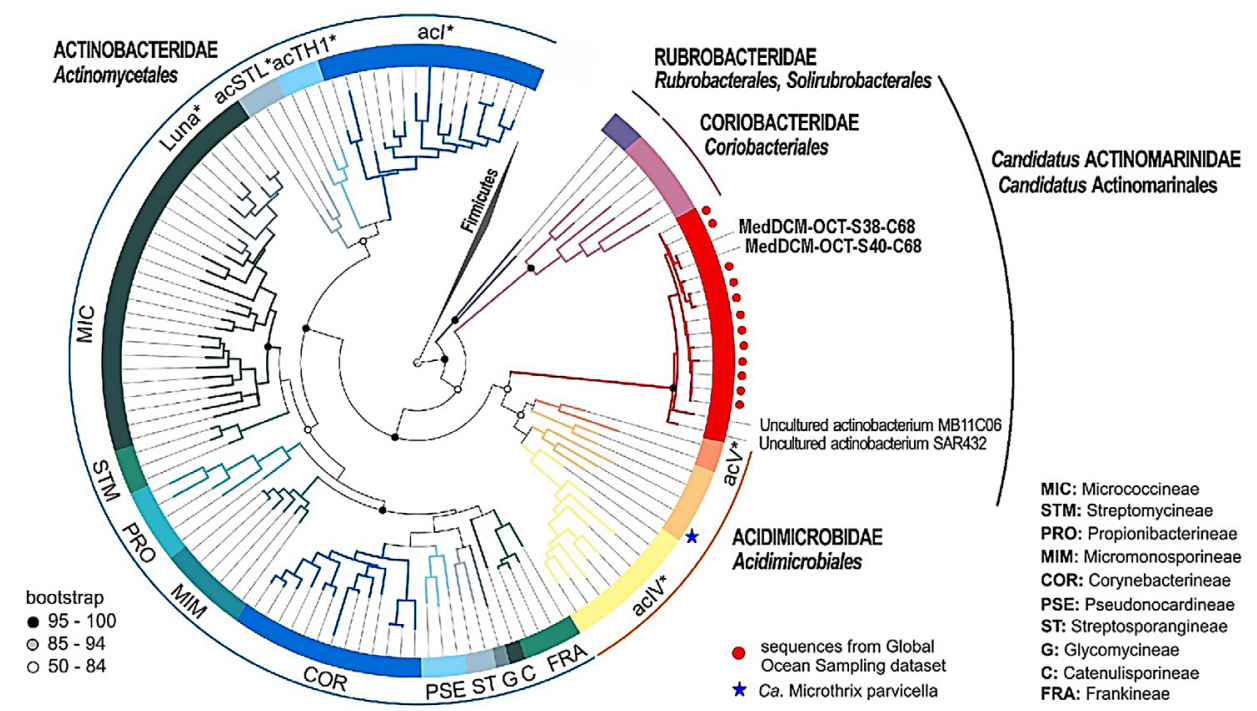

Fig. 16S rRNA phylogeny of some freshwater lineages in the context of the entire Actinobacteria phylum, with Firmicutes as the outgroup. Actinobacterial sub-classes are in bold uppercase and orders in bold italics. Sub-orders are shown in different colors in the tree and labeled (key is shown on bottom right). Freshwater actinobacterial clades are marked with black asterisk. Bootstrap values for all major branches are indicated by colored circles (see key bottom left) (Ghai et al., 2013).

and the genus Candidatus Nanopelagicus' - three species ('Ca. Nanopelagicus limnes', 'Ca. Nanopelagicus hibericus'and ' $C a$. Nanopelagicus abundans'). The strains isolated from Lake Soyang (Korea) are two more new species: ' $\mathrm{Ca}$. Planktophila rubra' and ' $\mathrm{Ca}$. Planktophila aquatilis' (Kim et al., 2019).

The isolated strains of the genus ' $\mathrm{Ca}$. Planktophila' and the genus ' $\mathrm{Ca}$. Nanopelagicus' are aerobic freeliving motionless photoheteotrophs. They have a very small cell size (from 0.012 to $0.061 \mu \mathrm{m} 3$ ), streamlined genome (from 1.16 to $1.46 \mathrm{Mb}$ ), genome with low $\mathrm{G}+\mathrm{C}$ content (less than 50\%), and carry genes for actinorhodopsins (Kang et al., 2017; Neuenschwander et al., 2018; Kim et al., 2019).

The acIV lineage is divided into four monophyletic clusters (acIV-A, acIV-B, acIV-C, and acIV-D) and six subclusters (Newton et al., 2011). It consists of uncultivated actinobacterial sequences obtained from various environments and includes cultivated strains of Actinobacteria, such as the strain Ilumatobacter fluminis YM22-133 isolated from the sediments of the estuary of the Kuiragawa River (Japan) (Matsumoto et al., 2009) and the strain Aquihabitans daechungensis CH22-21 (family Iamiaceae) isolated from the water reservoir Daechung (Korea) (Jin et al., 2013). These strains are aerobic free-living motionless chemoorganotrophs with a high G + C DNA content (68-72\%).

Analysis of the metagenomic sequences obtained from various lakes and estuaries indicated that the genomes acI and acIV have a low G + C DNA content, from 42 to $50 \%$ (Ghai et al., 2012). Although Actinobacteria are characterized as organisms with a high of G + C DNA content, both types of Actinobacteria together inhabit freshwater bodies.

The Luna1 lineage consists of four clusters, one of which, Luna1-A2, is the most numerous in the database of sequences (Hahn, 2009). New species of the isolated Actinobacteria belonging to this lineage and having
'Candidatus' status formed two Luna clusters. The name Luna originates from the name of Lake Mondsee (Moon Lake, Austria), from which the first strains of freshwater Actinobacteria with selenoid morphology (vibrio) were isolated (Hahn et al., 2003; Newton et al., 2011).

The first cluster Luna-1 (the Luna1 lineage) included strains with red pigments, such as ' $\mathrm{Ca}$. Rhodoluna lacicola', 'Ca. Planktoluna difficilis', 'Ca. Aquiluna rubra', ' $\mathrm{Ca}$. Rhodoluna limnophila', 'Ca. Rhodoluna planktonica', and ' $\mathrm{Ca}$. Limnoluna rubra', as well as one strain with yellow pigment, 'Ca. Flaviluna lacus' (Hahn, 2009). Based on phylogenetic, phenotypic and chemotaxonomic features, the obtained ' $\mathrm{Ca}$. Rhodoluna lacicola' strain is a new species Rhodoluna lacicola of the new genus Rhodoluna within the family Microbacteriaceae and order Micrococcales (Hahn et al., 2014). Another IMCC13023 strain belonging to 'Ca. Aquiluna rubra' was first isolated from seawater; then the similar 16S rRNA gene sequences with 99\% homology were also found in freshwater bodies (Kang et al., 2012). Unlike other known members of the family Microbacteriaceae, the strains Rhodoluna lacicola and IMCC1302 have ultra-micro sizes, a reduced genome (1.43 and $1.359 \mathrm{Mb}$, respectively) and low content of GC base pairs in DNA (51.5-51.7\%) (Kang et al., 2012; Hahn et al., 2014). The remaining strains from the Luna-1 cluster had the Candidatus status because they were obtained only in mixed culture with other non-actinobacterial strains (Hahn, 2009).

The second cluster Luna-2 (the acIII lineage) included only strains with yellow pigments, which had an unknown species status (Hahn et al., 2003).

Other lineages of freshwater Actinobacteria are minor and found only in some water bodies. The acV lineage is associated with bacteria isolated from soil, and it clusters with the soil group SoilII + III. The acSTL, acTH1 and acTH2 lineages do not have cultivated representatives and consist of clones obtained from 
the water of Lake Stechlin in Germany (acSTL) and Lake Taihu in China (acTH1 and acTH2) (Wu et al., 2007; Newton et al., 2011). Luna3 is closely related to other Luna groups but still also consists of uncultivated representatives.

In addition to the above, new groups of photoheterotrophic planktonic Actinobacteria were identified within the already known freshwater lineages. These Actinobacteria had a reduced small genome (1.16-1.32 $\mathrm{Mb}$ ) and different $\mathrm{G}+\mathrm{C}$ content (from 44 to $61 \%$ ) as well as possessed proteorhodopsins and actinorhodopsins (Ghai et al., 2014). These are the acMicro group in the acIII lineage (order Actinomycetales) and the acAcidi group in the order Acidimicrobiales.

\subsection{Phylogenetic groups of freshwater Actinobacteria in Lake Baikal}

In Lake Baikal, phylum Actinobacteria is one of the dominant groups (Parfenova et al., 2013; Zakharova et al., 2013; Gladkikh et al., 2014; Krasnopeev et al., 2016; Kurilkina et al., 2016; Bashenkhaeva et al., 2017; Cabello-Yeves et al., 2018; Kulakova et al., 2018), comprising approximately $30 \%$ of bacterioplankton (Parfenova et al., 2013; Bashenkhaeva et al., 2015; Mikhailov et al., 2015) and during spring blooming of phytoplankton - up to $57 \%$ of the bacterial community in the water column (Mikhailov et al., 2019), up to $14 \%$ of the microbial community of the endemic sponge Lubomirskia baikalensis (Gladkikh et al., 2014) and up to $44 \%$ of bacterial community in the lake sediments (Zemskaya et al., 2015).

Glöckner (2000) first discovered freshwater Actinobacteria in Lake Baikal. Molecular approach enabled identifying in the water column the species Planktophila limnetica (acI) typical of bacterioplankton (Parfenova et al., 2013; Gladkikh et al., 2014), the orders Actinomycetales and Acidimicrobiales as well as other unclassified Actinobacteria (Mikhailov et al., 2015; 2019). The genus Planktophila and the order Acidimicrobiales were found in all species of healthy Baikal sponges (Seo et al., 2016), and the representatives of the genera Ilumatobacter and Iamia (acIV) were identified in diseased sponges L. baicalensis and Baicalospongia intermedia (Krasnopeev et al., 2016). In the sub-ice waters, there were Actinobacteria of the genus Ilumatobacter (acIV) (Bashenkhaeva et al., 2015), freshwater acI ones, the acAcidi group, the family Acidimicrobiaceae and other unclassified Actinobacteria (Bashenkhaeva et al., 2017; CabelloYeves et al., 2018). Actinobacterial sequences of the genus Ilumatobacter were also detected in the deep near-bottom layers in the lake (Zakharova et al., 2013). In gas- and oil-bearing sediments, Actinobacteria belonging to the acI (family Sporichteaceae, hgcI group) and acIV (family Acidimicrobiaceae) were identified (Zemskaya et al., 2015).

To date, no strain of the known freshwater lineages of Actinobacteria has been isolated from Lake Baikal.

\section{Conclusion}

Therefore, over two past decades since the discovery of the first freshwater Actinobacteria, nine monophyletic freshwater lineages belonging to the classes Actinobacteria and Acidimicrobia within the phylum Actinobacteria have been identified. Pure and mixed cultures of Actinobacteria belonging to different freshwater lineages, such as acI, acIV, Luna1, and acIII, have been obtained. Another new order, ' $\mathrm{Ca}$. Nanopelagicales', within the class Actinobacteria has been proposed. The presented unified classification is not final and is being supplemented. Further studies to identify new phylogenetic groups of actinobacteria in freshwater environments and to isolate and cultivate new previously uncultivated representatives of freshwater Actinobacteria are promising, necessary and important because they form the basis for subsequent ecological research on the role of freshwater Actinobacteria in the natural habitat.

\section{Acknowledgments}

The study was carried out within the framework of State Task No. 0345-2019-0003 (AAAA-A16-116122110061-6).

\section{References}

Allgaier M., Grossart H.-P. 2006. Diversity and seasonal dynamics of Actinobacteria populations in four lakes in northeastern Germany. Applied Environmental Microbiology 72: 3489-3497. DOI: 10.1128/AEM.72.5.3489-3497.2006

Barka E.A., Vatsa P., Sanchez L. et al. 2016. Taxonomy, physiology, and natural products of Actinobacteria. Microbiology and Molecular Biology Reviews 80: 1-43. DOI: 10.1128/MMBR.00019-15

Bashenkhaeva M.V., Zakharova Yu.R., Petrova D.P. et al. 2015. Sub-ice microalgal and bacterial communities in freshwater Lake Baikal, Russia. Microbial Ecology 70: 751-765. DOI: 10.1007/s00248-015-0619-2

Bashenkhaeva M.V., Zakharova Yu.R., Galachyants Yu.P. et al. 2017. Bacterial communities during the period of massive under-ice dinoflagellate development in Lake Baikal. Microbiology 86: 524-532. DOI: 10.1134/ S0026261717040038

Cabello-Yeves P.J., Zemskaya T.I., Rosselli R. et al. 2018. Genomes of novel microbial lineages assembled from the sub-ice waters of Lake Baikal. Applied Environmental Microbiology 84: 1-21. DOI: 10.1128/AEM.02132-17

Ghai R., McMahon K.D., Rodriguez-Valera F. 2012. Breaking a paradigm: cosmopolitan and abundant freshwater actinobacteria are low GC. Environmental Microbiology Reports 4: 29-35. DOI: 10.1111/j.1758-2229.2011.00274.x

Ghai R., Mizuno C.M., Picazo A. et al. 2013. Metagenomics uncovers a new group of low GC and ultra-small marine Actinobacteria. Scientific Reports 3. DOI: 10.1038/srep02471

Ghai R., Mizuno C.M., Picazo A. et al. 2014. Key roles for freshwater Actinobacteria revealed by deep metagenomic sequencing. Molecular Ecology 23: 6073-6090. DOI: 10.1111/ mec. 12985

Gladkikh A.S., Kaluzhnaya O.V., Belykh O.I. et al. 2014. Analysis of bacterial communities of two Lake Baikal endemic sponge species. Microbiology 83: 787-797. DOI: 10.1134/ s002626171406006x 
Glöckner F.O., Zaichikov E., Belkova N. et al. 2000. Comparative 16S rRNA analysis of lake bacterioplankton reveals globally distributed phylogenetic clusters including an abundant group of Actinobacteria. Applied Environmental Microbiology 66: 5053-5065. DOI: 10.1128/ AEM.66.11.5053-5065.2000

Goodfellow M., Williams S.T. 1983. Ecology of actinomycetes. Annual Review of Microbiology 37: 189-216. DOI: 10.1146/annurev.mi.37.100183.001201

Hahn M.W., Lunsdorf H., Wu Q. et al. 2003. Isolation of novel ultramicrobacteria classified as Actinobacteria from five freshwater habitats in Europe and Asia. Applied Environmental Microbiology 69: 1442-1451. DOI: 10.1128/ AEM.69.3.1442-1451.2003

Hahn M.W. 2009. Description of seven candidate species affiliated with the phylum Actinobacteria, representing planktonic freshwater bacteria. International Journal of Systematic and Evolutionary Microbiology 59: 112-117. DOI: 10.1099/ijs.0.001743-0

Hahn M.W., Schmidt J., Taipale S.J. et al. 2014. Rhodoluna lacicola gen. nov., sp. nov., a planktonic freshwater bacterium with stream-lined genome. International Journal of Systematic and Evolutionary Microbiology 64: 3254-3263. DOI: $10.1099 / \mathrm{ijs}$.0.065292-0

Hiorns W.D., Methe B.A., Nierzwicki-Bauer S.A. et al. 1997. Bacterial diversity in Adirondack mountain lakes as revealed by $16 \mathrm{~S}$ rRNA gene sequences. Applied Environmental Microbiology 63: 2957-2960.

Humayoun S.B., Bano N., Hollibaugh J.T. 2003. Depth distribution of microbial diversity in Mono lake, a meromictic Soda lake in California. Applied Environmental Microbiology 69: 1030-1042. DOI: 10.1128/AEM.69.2.1030-1042.2003

Humbert J.F., Dorigo U., Cecchi P. et al. 2009. Comparison of the structure and composition of bacterial communities from temperate and tropical freshwater ecosystems. Environmental Microbiology 11: 2339-2350. DOI: $10.1111 /$ j.1462-2920.2009.01960.x

Jezbera J., Sharma A.K., Brandt U. et al. 2009. 'Candidatus Planktophila limnetica', an actinobacterium representing one of the most numerically important taxa in freshwater bacterioplankton. International Journal of Systematic and Evolutionary Microbiology 59: 2864-2869. DOI: 10.1099/ ijs.0.010199-0

Jin L., Huy H., Kim K.K. et al. 2013. Aquihabitans daechungensis gen. nov., sp. nov., an actinobacterium isolated from reservoir water. International Journal of Systematic and Evolutionary Microbiology 63: 2970-2974. DOI: 10.1099/ ijs.0.046060-0

Kang I., Lee K., Yang S.J. et al. 2012. Genome sequence of 'Candidatus Aquiluna' sp. strain IMCC13023, a marine member of the Actinobacteria isolated from an arctic fjord. Journal of Bacteriology 194: 3550-3551. DOI: 10.1128/ JB.00586-12

Kang I., Kim S., Islam M.R. et al. 2017. The first complete genome sequences of the acI lineage, the most abundant freshwater Actinobacteria, obtained by whole genomeamplification of dilution to-extinction cultures. Scientific Reports 7. DOI: $10.1038 /$ srep42252

Kim S., Kang I., Seo J-H. et al. 2019. Culturing the ubiquitous freshwater actinobacterial acI lineage by supplying a biochemical 'helper' catalase. The ISME Journal 13: 22522263. DOI: 10.1038/s41396-019-0432-x

Krasnopeev A.Yu., Bukshuk N.A., Potapov S.A. et al. 2016. Genetic diversity of bacterial communities associated with diseased sponges of Lake Baikal. Izvestiya Irkutskogo Gosudarstvennogo Universiteta. Seriya "Biologiya. Ekologiya" [The bulletin of Irkutsk State University. Series "Biology. Ecology"] 16: 3-14. (in Russian)

Kulakova N.V., Sakirko M.V., Adelshin R.V. et al. 2018.
Brown rot syndrome and changes in the bacterial community of the Baikal sponge Lubomirskia baicalensis. Microbial Ecology 75: 1024-1034. DOI: 10.1007/s00248-017-1097-5

Kurilkina M.I., Zakharova Yu.R., Galachyants Yu.P. et al. 2016. Bacterial community composition in the water column of the deepest freshwater Lake Baikal as determined by nextgeneration sequencing. FEMS Microbiology Ecology 92. DOI: 10.1093/femsec/fiw094

Ludwig W., Euzéby J., Schumann P. et al. 2012. Road map of the phylum Actinobacteria. In: Goodfellow M. (Ed.), Bergey's manual of systematic bacteriology. New York, pp. 1-28.

Martinez-Garcia M., Swan B.K., Poulton N.J. et al. 2012. High-throughput single-cell sequencing identifies photoheterotrophs and chemoautotrophs in freshwater bacterioplankton. The ISME Journal 6: 113-123. DOI: 10.1038/ismej.2011.84

Matsumoto A., Kasai H., Matsuo Y. etal. 2009. Ilumatobacter fluminis gen. nov., sp. nov., a novel actinobacterium isolated from the sediment of an estuary. The Journal of General and Applied Microbiology 55: 201-205. DOI: 10.2323/ jgam.55.201

Methe' B.A., Hiorns W.D., Zehr J.P. 1998. Contrasts between marine and freshwater bacterial community composition-analyses of communities in Lake George and six other Adirondack lakes. Limnology and Oceanography 43: 368-374. DOI: 10.4319/1o.1998.43.2.0368

Mikhailov I.S., Zakharova Yu.R., Galachyants Yu.P. et al. 2015. Similarity of structure of taxonomic bacterial communities in the photic layer of Lake Baikal's three basins differing in spring phytoplankton composition and abundance. Doklady Biochemistry and Biophysics 465: 413-419. DOI: 10.1134/S1607672915060198

Mikhailov I.S., Zakharova Y.R., Bukin Y.S. et al. 2019. Co-occurrence networks among bacteria and microbial eukaryotes of Lake Baikal during a spring phytoplankton bloom. Microbial Ecology 77: 96-109. DOI: 10.1007/ s00248-018-1212-2

Neuenschwander S.M., Ghai R., Pernthaler J. et al. 2018. Microdiversification in genome-streamlined ubiquitous freshwater Actinobacteria. The ISME Journal 12: 185-198. DOI: $10.1038 /$ ismej.2017.156

Newton R.J., Jones S.E., Eiler A. et al. 2011. A guide to the natural history of freshwater lake bacteria. Microbiology and Molecular Biology Reviews 75: 14-49. DOI: 10.1128/ MMBR.00028-10

Parfenova V.V., Gladkikh A.S., Belykh O.I. 2013. Comparative analysis of biodiversity in the planktonic and biofilm bacterial communities in Lake Baikal. Microbiology 82: 94-105. DOI: 10.1134/S0026261713010128

Parveen B., Reveilliez J.-P., Mary I. et al. 2011. Diversity and dynamics of free-living and particleassociated Betaproteobacteria and Actinobacteria in relation to phytoplankton and zooplankton communities. FEMS Microbiology Ecology 77: 461-476. DOI: 10.1111/j.1574-6941.2011.01130.x

Rappe' M.S., Gordon D.A., Vergin K.L. et al. 1999. Phylogeny of actinobacteria small subunit (SSU) rRNA gene clones recovered from arine bacterioplankton. Systematic and Applied Microbiology 22: 106-112. DOI: 10.1016/ S0723-2020(99)80033-2

Sen A., Daubin V., Abrouk D. et al. 2014. Phylogeny of the class Actinobacteria revisited in the light of complete genomes. The orders 'Frankiales' and Micrococcales should be split into coherent entities: proposal of Frankiales ord. nov., Geodermatophilales ord. nov., Acidothermales ord.nov. and Nakamurellales ord. nov. International Journal of Systematic and Evolutionary Microbiology 64: 3821-3832. DOI: 10.1099/ ijs.0.063966-0 
Seo E.Y., Jung D., Belykh O.I. et al. 2016. Comparison of bacterial diversity and species composition in three endemic Baikalian sponges. International Journal of Limnology: Annales de Limnologie 52: 27-32. DOI: 10.1051/ $\operatorname{limn} / 2015035$

Urbach E., Vergin K.L., Young L. et al. 2001. Unusual bacterioplankton community structure in ultra-oligotrophic Crater Lake. Limnology and Oceanography 46: 557-572. DOI: 10.4319/lo.2001.46.3.0557

Ventura M., Canchaya C., Tauch A. et al. 2007. Genomics of Actinobacteria: tracing the evolutionary history of an ancient phylura. Microbiology and Molecular Biology Reviews 71: 495-548. DOI:10.1128/MMBR.00005-07

Warnecke F., Amann R., Pernthaler J. 2004. Actinobacterial 16S rRNA genes from freshwater habitats cluster in four distinct lineages. Environmental Microbiology 6: 242-253. DOI: 10.1111/j.1462-2920.2004.00561.x

Wu Q.L., Zwart G., Wu J. et al. 2007. Submersed macrophytes play a key role in structuring bacterioplankton community composition in the large, shallow, subtropical Taihu Lake, China. Environmental Microbiology 9: 27652774. DOI: $10.1111 /$ j.1462-2920.2007.01388.x

Zakharova Yu.R., Galachyants Yu.P., Kurilkina M.I. et al. 2013. The structure of microbial community and degradation of diatoms in the deep near-bottom layer of Lake Baikal. PLOS ONE 8: 1-12. DOI: 10.1371/journal.pone.0059977

Zemskaya T.I., Lomakina A.V., Mamaeva E.V. et al. 2015. Bacterial communities in sediments of Lake Baikal from areas with oil and gas discharge. Aquatic Microbial Ecology 76: 95-109. DOI: $10.3354 /$ ame01773

Zwart G., Crump B.C., Agterveld M.P. et al. 2002. Typical freshwater bacteria: an analysis of available 16S rRNA gene sequences from plankton of lakes and rivers. Aquatic Microbial Ecology 28: 141-155. DOI: 10.3354/ame028141 